\title{
The Governance of Education Foundation in Private Universities: Problems, Experiences and Ways of Promotion
}

\author{
Jie LIU
}

Ningbo Dahongying University, Ningbo, Zhejiang, China

\author{
Keywords: University; Education Foundation; Governance.
}

\begin{abstract}
China's university education Foundation started late, although in support of the development of education in colleges and universities to achieve a certain degree, but there are dual management models, low social credibility, the donation system is not perfect, such as a series of governance issues. After several decades of exploration and development, Zhejiang University's Education fund has developed to take shape and maturity, draw lessons from Zhejiang University's concrete practices and practices, and actively promote the governance path of our university education Foundation, thus promoting the healthy development of our university education Foundation. At the same time, it can promote the healthy development of China's private university education Foundation.
\end{abstract}

\section{Introduction}

According to the Foundation Center network Statistics, as of 2015, the National University Education Foundation altogether 454. With the increasing influence of higher education Foundation, it plays an increasingly important role in supplementing school funding. Although the development of university education Foundation in our country has achieved some achievements, the Foundation's development has various problems because of the short development time,, especially under the background of modernization of governance ability, the foundation's governance problem appears to be more outstanding. Under the background of the modernization of national governance system and governance ability, it is of great significance to improve the level of university governance and promote the healthy development of higher education in China.

\section{Problems with the Governance of China's University Education Foundation}

Jinan University Education Foundation is China's first established Education Foundation, Tsinghua University Education Foundation and Beijing University Education Foundation were established in 1994 and 1995 respectively. The foundation of college education in our country started late, although some achievements have been made in recent years, there are many problems in governance, which restricts the development of university Education Foundation in China.

\subsection{The Traditional Management Mode of Dual Leadership}

According to the Foundation management Regulations, the University Education Foundation of China has established the internal management system which is responsible for decision-making by the board, supervising and managing, and the Secretariat responsible for implementation. The foundation generally accepts the double management of the business competent department and the registration Department, develops under the double system. Although the decision of the foundation is made by the Governing Council, since most of our university education Foundation belongs to the level two functional department, in order to control the risk, the business competent department will make personnel arrangements for the members of the board, most of whom are concurrently the school leaders. As a result, the decision-making power of the Council is actually in the hands of the school leaders, and the foundation is not free to operate as an independent legal person, which is actually an extension of the university administrative system and the administrative logic in the foundation. This dual leadership management model severely restricts the foundation's flexibility and development space and influences its operational efficiency. 


\subsection{The Foundation's Social Credibility is Low}

Transparency of financial disclosure is an important condition for the foundation's continuous operation. The university Education Foundation, as a non-profit organization, should actively disclose financial information to the public, actively accept the supervision and inspection of the public, and ensure the transparency and openness of financial information. The foundation Transparency Index (FTI) is an important index to measure the information disclosure of the foundation. The FTI score below 50 indicates a low level of information disclosure by the Foundation, and that financial information and capital operations are not publicly transparent. Overall, the Foundation Information Disclosure degree is low, the social credibility is low. In addition, although many university education foundations have its own website, but neglects the management and the maintenance, has not been able to update the relevant information in time. And, from the income sources of many university education foundations, the income from social donations is almost Nil. This shows that the foundation's social credibility is low and it has not been able to win the trust of the public.

\subsection{The Donation System of China's University Foundations is not Perfect yet}

In order to encourage donations from all walks of life to education, Article 9 of the "People's Republic of China Corporate Income Tax Law" stipulates that the public welfare donation expenses incurred by an enterprise shall be deducted when calculating the taxable income within the portion of the total annual profit of less than $12 \%$. This provision is only a general reference to the granting of tax incentives. It does not explicitly specify the level of specific tax benefits and how to enjoy preferential policies. Although the "Tax Law" clearly stipulates tax benefits for social donations, there are many restrictions on the institutions that enjoy these tax benefits, and the approval process is cumbersome and complex, virtually increasing the threshold of social donations and shutting out some social donations.

\section{Successful Cases of Zhejiang University Education Foundation}

Zhejiang University Zhu Kezhen Education Foundation was established in 1994. In 2006, it was re-registered in the Ministry of Civil Affairs and officially changed its name to Zhejiang University Education Foundation. After more than 10 years of exploration and development, a relatively complete fund operation management model has been formed.

\subsection{Diversified Fund Operation Mode}

The development and expansion of the foundation not only depends on the raising of funds, but also requires effective investment to realize the maintenance and appreciation of the fund and realize the rolling development of "investment-value-adding-reinvestment". For foundations, effective investment and value-added are important guarantees for the foundation's life and development. The Zhejiang University Foundation has successfully realized the maintenance and appreciation of funds by depositing funds in a diversified fund operation mode such as banking, school-enterprise cooperation, and market-oriented operation.

\subsection{Adhere to the Strategy of Brand Characteristics, Gathering Alumni Resources}

As a university alumnus of Zhejiang University, they have a deep feeling of affection for their alma mater, hoping to reward their alma mater's cultivation thanks to their success in their careers. It is the alumni's feeling that alumni donation has become an important fund for Zhejiang University Education Foundation. As a well-known university, Zhejiang University has cultivated many successful entrepreneurs who have given material support to the Zhejiang University Education Foundation. In May 2017, donated by Shanghai Zhenzhen Investment Management Co., Ltd. will donate 1.1 billion yuan to promote Zhejiang University to build a world-class university; in the same year, Zhongmei Group donated 30 million yuan to support the innovation and development of Zhejiang University; in December, Zhejiang Wei Jian Technology Co., Ltd. donated 5 million yuan to Zhejiang University Education Foundation. 


\subsection{Set up a Special Fund}

The special fund is a dedicated fund that is set according to the needs of school development. The special funds currently set by the Zhejiang University Education Foundation include: Disciplinary Development Funds, Capital Construction Funds, Student Culture Funds, Teacher Development Funds, Faculty Development Funds, School Development Funds, Social Welfare Funds, and Special Development Funds for Key Projects. By setting up a special fund, it can not only attract various industries to participate in the construction and development of schools, but also can mobilize the enthusiasm of the school counterparts to raise funds. As of 2017, Zhejiang University Education Foundation's special fund assets amounted to 1.76 billion yuan.

\subsection{Establishment of Overseas Foundation}

Due to the great differences in economic environment and legal environment at home and abroad, foreign recognition of social donations for running schools is high. The United States has a long tradition of donation and has a tradition of giving donations to schools, philanthropy, and public welfare. In addition, the U.S. donation system is superior to the domestic one, and the conditions for donation are also relatively loose, which is also one of the motivations for attracting social donations. The Zhejiang University Education Foundation recognized the relatively good donation system overseas. In 1995, the Hong Kong Zhejiang University Zhu Kezhen Education Foundation was established in Hong Kong. In 1996, the Zhu Ke Education Foundation of Zhejiang University in North America was established. Since the foundation of these foundations, these foundations have been playing a major role in supporting the development and construction of schools.

\section{Zhejiang University Education Foundation's Governance Experience for Reference}

Zhejiang University Education Foundation's healthy development, on the one hand benefits from the foundation specialized management structure, on the other hand can not be separated from the foundation good social credibility, Zhejiang University Foundation's Transparency index is divided into 78.8, in Zhejiang Province 602 Foundation ranks upstream. The management experience of Zhejiang University Education Foundation is embodied in three aspects:

\subsection{Professional Foundation Management Team}

Zhejiang University Education Foundation has professional foundation management personnel, including finance, finance, investment, public relations and other professional personnel. This professional team not only guaranteed the foundation's healthy operation, at the same time, through their publicity and planning, to achieve the fund's value added. This is not only rely on bank interest to achieve, but also rely on their professional investment and financial knowledge, to invest in stocks, securities, real estate and other ways to increase the value of the fund, to achieve a higher return on investment.

\subsection{Making Full Use of Alumni Resources}

Alumni are a valuable resource of a university and an important force to support the development of the school, they often contribute their own strength to the alma mater, one of the important performances is to donate money to the alma mater. Therefore, the University should actively liaise with alumni, nurture the important motivation of the recruitment work, through various activities to attract alumni to actively participate in. Zhejiang University has organized tens of thousands of yuan in teaching buildings and funds directly donated by alumni through large-scale activities such as school celebrations. Throughout the development of the Education foundation of Zhejiang University, overseas alumni have played an active role in the development of the foundation, according to the statistics, the overseas alumni and alumni Enterprises donated $75 \%$ of the total amount of donations to the school.

\subsection{The Extensive Development of School-Enterprise Cooperation}

Through the development of school-enterprise cooperation, not only to achieve joint school, but 
also to use the advantages of both sides to achieve their respective growth, to achieve a "double win." Through the matchmaking of directors, and constantly broaden the field of cooperation with enterprises. May 2017, Shanghai Real Investment Management Co., Ltd. set up the "Zhejiang University Education Foundation, the True Education Development Fund", will continue to donate 1.1 billion yuan for 10 years to help push Zhejiang University to build world-class university. Their cooperation is the system innovation of social participation in running a school, which embodies the combination of financial capital and university, talent and technology, to achieve the common development of enterprises and universities.

\section{The Way to Promote the Healthy Development of University Education Foundation in China}

Most of the education foundations in China have not been established for a long time. There are many problems that restrict the healthy development of the foundation. Through studying and summarizing the successful experience of the Zhejiang University Education Foundation, and combining the actual conditions of various universities, the University of China Education Foundation has achieved a healthy development.

The traditional dual management system severely limits the development of our foundation and must establish a scientific management model. Learning from the governance framework of the Zhejiang University Education Foundation, establish an organizational structure and governance framework with its own development characteristics. An organizational framework is set up with the fund council as the decision-making body. The school leader serves as the chairman, and the council is responsible for formulating the development strategy of the foundation and ensuring the independence of the foundation. The board of directors has an operating department and a business department. The operation department is mainly responsible for the value-maintaining and value-added businesses of funds, and handing over capital operation businesses to professional investment management companies. It can be seen that the realization of the governance and development of the University Education Foundation is inseparable from the scientific management model and governance institutions. In addition, we must continue to promote the credibility of the University Education Foundation and improve the external security system of the University Education Foundation to achieve the governance of the University Education Foundation. In addition, we should continue to promote the credibility of university education Foundation and improve the external security system of university education Foundation, and realize the governance of University Education Foundation.

The popularization of education promotes the rapid development of the private university, as of 2017, the national General University 2631, of which the number of private universities is 742 , accounting for $28.2 \%$, the private university has become a supplement to our higher education is an important force Because of the lack of government financial support, the shortage of running funds is a short board restricting the development of private universities. The sustainable development of university can not be separated from the financial support, in the process of China's economic restructuring and higher education financial system reform, the University Education Foundation is of great value in realizing the diversification of university education funds, enhancing the autonomy of university running and promoting the overall development of higher education. Therefore, for the development of the private university, we can learn from the development experience of Zhejiang University Education Foundation, realize the development of the Education foundation of the private university, and solve the development predicament of the fund shortage.

\section{Acknowledgement}

This article is a research project of Ningbo City's philosophy and social sciences in 2018, "Study on the Establishment and Development of Private Colleges and Universities Education Foundation under the Background of New Citizens' Facilitative Law" (G18-ZXLL53). 


\section{References}

[1] Lu Changyu, Dai Xiaoping. Investment Status, Problems and Countermeasures of University Education Foundation in China [J]. Journal of Shanghai Finance University, 2014 (4).

[2] Guo Xiujing. Analysis of Current Situation of University Education Foundation in China and Choice of Development Path [J]. Journal of Tianjin University, 2009 (5).

[3] Zhang Lu. Analysis of the status quo of China's colleges and universities' foundation and development countermeasures--taking the Jiangnan University Education Development Foundation as an example [J]. Education Theory Research, 2016 (1).

[4] Chen Xiufeng. Contemporary Chinese University Foundation Research [M]. Beijing: China Social Sciences Press, 2010.

[5] Wu Shanghai. Analysis of the Development of University Education Foundation [J]. Higher Education Forum, 2010 (8).

[6] Zhejiang University Education Foundation website. http://www.zuef.zju.edu.cn/. 